\title{
Dispersion stability and exothermic properties of DNA-functionalized single-walled carbon nanotubes
}

This article was published in the following Dove Press journal:

International Journal of Nanomedicine

7 April 201 I

Number of times this article has been viewed

Minoru Kawaguchi ${ }^{1,2}$

Jun Ohno ${ }^{2,3}$

Akihito Irie ${ }^{4}$

Tadao Fukushima ${ }^{2,5}$

Jun Yamazaki ${ }^{2,6}$

Naotoshi Nakashima ${ }^{2,7}$

'Department of Dental Engineering, Biomaterials Section, Fukuoka Dental College, Sawara-ku, Fukuoka, Japan; 2Japan Science and Technology Agency (JST), Core Research of Evolutional Science and Technology (CREST), Chiyoda-ku, Tokyo, Japan; ${ }^{3}$ Department of Morphological Biology, Pathology Section, Fukuoka Dental College, Sawara-ku, Fukuoka, Japan; ${ }^{4}$ Department of Oral Rehabilitation, Section of Oral Implantology, Fukuoka Dental College, Sawara-ku, Fukuoka, Japan; ${ }^{5}$ Department of Dental Engineering, Bioengineering Section, Fukuoka Dental College, Sawara-ku, Fukuoka, Japan; ${ }^{6}$ Department of Physiological Science and Molecular Biology, Section of Cellular and Molecular Regulation, Fukuoka Dental College, Sawara-ku, Fukuoka, Japan; ${ }^{7}$ Department of Applied Chemistry, Graduate School of Engineering, Kyushu University, Nishi-ku, Fukuoka, Japan
Correspondence: Minoru Kawaguchi Department of Dental Engineering, Biomaterials Section, Fukuoka Dental College, 2-I5-I. Tamura, Sawara-ku, Fukuoka 8|4-0193, Japan

$\mathrm{Tel}+8$ I 9280I 04II

$\mathrm{Fax}+8 \mid$ 9280I 4909

Email kawagum@college.fdcnet.ac.jp
Abstract: Carbon nanotubes act as a photon antenna that serves as an effective "molecular heater" around the near-infrared (NIR) region. This exothermic generation can be used as a possible heating source for hyperthermia therapy. The current study reports the dispersible and exothermic properties with NIR irradiation for single-walled carbon nanotubes (SWNTs) treated with a strong acid (acid-treated SWNTs), and the SWNTs further functionalized with double-stranded DNA (DNA-functionalized SWNTs: DNA-SWNTs). DNA-SWNTs significantly improved the dispersibility of SWNTs when compared with the acid-treated SWNTs. The binding ratio of the acid-treated SWNT and DNA was calculated to be 3.1 (DNA/SWNTs) from the phosphorous content in the DNA-SWNT. This interaction of the SWNTs and DNA would contribute to the stable dispersion of the DNA-SWNTs in a culture medium. With NIR irradiation by a halogen lamp light source, the acid-treated SWNTs and the DNA-SWNTs showed strong heat evolution in vitro (in a culture medium) and in vivo (in the subcutaneous tissue of a mouse) condition without any invasive effect on the non-SWNT area. The results of this study suggested that the functionalization with DNA was an efficient approach to improve the dispersibility of SWNTs in body fluids, and the DNA-SWNT would be a promising source for photo-induced exothermic generation.

Keywords: DNA functionalization, near-infrared irradiation

\section{Introduction}

Carbon nanotubes (CNTs) have been considered for application in various biomedical systems, including intercellular molecular delivery and drug delivery. ${ }^{1-3}$ The unique properties of CNTs include their strong optical absorbance in the near-infrared (NIR) region, which could release significant heat. This exothermic generation potential by NIR irradiation can be used for hyperthermia cancer therapy. ${ }^{4-7}$ Kam et al ${ }^{8}$ prepared a water-soluble single-walled carbon nanotube (SWNT) by conjugation of the SWNTs and single-stranded DNA, and functionalized by polyethyleneglycol with the target ligand including folic acid as the tumor marker. They showed that the SWNT can be selectively internalized into cancer cells with very specific tumor markers and that NIR irradiation of the SWNTs can trigger thermal cell death without damage to normal cells.

To obtain selective targeted cell attachment of CNTs in the human body, a stable solubility (dispersibility) and smart delivery potential of functionalized CNTs will be needed as well as their nontoxic property. For the toxic property, several reports have demonstrated that soluble (acid-treated) and nonaggregated CNTs are not toxic to primary immune cells and that the increased sidewall functionalization of CNTs decreased the 
level of cytotoxicity for human dermal fibroblasts. ${ }^{8-13}$ The treatment of CNTs with strong acids produced carboxylic groups on the surface of the CNTs, and the treated CNTs can be dispersed in aqueous systems. ${ }^{14,15}$ Although the acid treatment of SWNTs would be one way to functionalize the SWNTs, the result of our preliminary experiment revealed that the acid-treated SWNT formed aggregated particles when added to a cell cultural medium. This result suggested that a further functionalization to improve the dispersibility of the acid-treated SWNTs in body fluids is needed.

The conjugates of CNTs and DNA will have potential uses in many fields such as nucleic acid sensing, genetherapy, and solubilization in aqueous media. ${ }^{16}$ Since Nakashima et $\mathrm{al}^{17}$ reported that the double-stranded DNA molecules were an effective solubilizer of SWNTs, the single- and double-stranded DNA molecules were used as solubilizer of CNTs for biomedical purposes. We expected that the functionalization with double-stranded DNA would be an effective approach to improve the stability of the dispersibility of the acid-treated SWNT in the human body. However, there were no reports on the dispersability and the exothermic property of the DNA-functionalized acid-treated SWNT (DNA-SWNT).

The future goal of our study is the preparation of a smartdeliverable SWNT which can more selectively attach to tumor cells by conjugation of the functionalized acid-treated SWNT with a specific antibody of the targeted tumor cells. The acidtreated SWNT would have the potential to bind covalently to the specific antibody via the carboxylic acid group formed on the surface of SWNT. In the first stage of our project, we designed the DNA-SWNT as a base model for an exothermic device to improve stable dispersibility in body fluids.

Generally, the continuous-wave laser was used as NIR light source for conversion into heat in previous reports. However, data are needed with regard to the exothermic property by using a conventional halogen light as an NIR light source because the halogen light source has advantages such as convenient handling and is noninvasive for tissues. Herein, we report the dispersion stability of the DNA-SWNT and the exothermic property of the DNA-SWNT irradiated with halogen-type NIR. The purpose of this study was to investigate the exothermic efficacy of the DNA-SWNT combined with a halogen light NIR source. For this purpose, we first investigated the exothermic generation of the acid-treated SWNT in a culture medium with different SWNT concentrations, and then examined the heat generation of the SWNTcontaining gel injected into the back of mice to compare actual heat generation in vivo. To improve the stability of the dispersed SWNTs in the body fluid, DNA-SWNTs were prepared and the exothermic generation in vitro and in vivo examined. We demonstrated that heat generation of the acidtreated SWNT and DNA-SWNT irradiated by NIR and the stable dispersibility of the DNA-SWNT.

\section{Materials and methods Preparation of acid-treated SWNT}

SWNTs (400 mg, main range diameter of $1 \mathrm{~nm}$ and average length of $800 \mathrm{~nm}$, CG100, SouthWest Nanotechnology, Norman, OK, USA) were poured into a mixture of $300 \mathrm{~mL}$ of sulfuric acid and $100 \mathrm{~mL}$ of nitric acid, and the mixture was sonicated using a bath-type sonicator (Type 1510, Branson, Danbury, USA) for 7 hours at $40^{\circ} \mathrm{C}$. After this treatment, the product was vacuum filtered using a polytetrafluoroethylene (PTFE) membrane (pore size of $0.2 \mu \mathrm{m}$ ). The resultant solid was washed with deionized water and dissolved in $10 \mathrm{~mL}$ of water, and then freeze-dried.

\section{Preparation of DNA-SWNT}

Several researchers have reported that DNA can wrap around SWNTs through noncovalent interactions, thus rendering them soluble in aqueous solutions. ${ }^{17-20}$ We expected that the functionalization of the SWNTs by DNA wrapping would be more stable in the body fluids. We prepared the DNA-SWNT aqueous solution according to previously reported methods. ${ }^{17}$ The acid-treated SWNT $(10 \mathrm{mg})$ and DNA (100 mg, derived from salmon testis, average 300-bp, Maruha-Nichiro Holdings, Tokyo, Japan) were sonicated (90W, Type 1510, Branson, Danbury, USA) in deionized water $(10 \mathrm{~mL})$ for 1 hour. The resultant aqueous solution of the DNA-SWNT (1 mg/mL, based on SWNT amount) was subjected to the following experiments.

\section{Transmission electron microscopy (TEM) observation}

The particle morphology and structure of the SWNT samples (untreated SWNT, acid-treated SWNT, and DNA-SWNT) were analyzed by TEM (JEM 2000FX, JEOL, Tokyo, Japan). The dispersed SWNTs in deionized water were dried on 400-mesh copper grids coated with carbon. Images were captured using a $200 \mathrm{kV}$ accelerating voltage.

\section{Examination of SWNT dispersibility}

Cultures (MEM-alpha, 1X low glucose, Invitrogen, Tokyo, Japan) containing different concentrations of the SWNT (acid-treated SWNT and DNA-SWNT, 0.01, 0.1, 0.25, and $0.5 \mathrm{mg} / \mathrm{mL})$ were prepared. These cultures $(1 \mathrm{~mL})$ were 
centrifuged at $6600 \mathrm{rpm}$ for 5 minutes at 1, 10, 24, and 48 hours after being prepared. The supernatant of the centrifuged sample was measured in the transmittance mode at $500 \mathrm{~nm}$ by ultraviolet-visible spectroscopy (V-560 spectrophotometer, Jasco, Tokyo, Japan), and the change in the transmittance was determined for evaluating the stability of the dispersed SWNT in the culture medium $(n=3)$. The precipitate formation of the SWNTs in the culture medium was observed under microscope (TS-100, Nikon, Tokyo, Japan). One mL of mixture of the medium and the SWNTs (the acid-treated SWNT and the DNA-SWNT, concentration of $0.25 \mathrm{mg} / \mathrm{mL}$ ) was poured into a well of a 48 -well multiplate. Five minutes after being mixed, an image of each sample was observed and captured. All procedures were conducted at $25^{\circ} \mathrm{C}$.

\section{Binding ratio of SWNT and DNA}

To examine the binding ratio of the acid-treated SWNT and DNA, the phosphorous content of the DNA-SWNT was determined by inductively coupled plasma (ICP) emission spectrometry analyses. Based on the phosphorous amount of the DNA-SWNT, we estimated the number of DNA molecules bound to the acid-treated SWNT molecule. The DNA-SWNT solution ( $1 \mathrm{mg} / \mathrm{mL})$ was ultracentrifuged $\left(5 \times 10^{4} \mathrm{rpm}\right)$ for 60 minutes, then filtrated though a $0.2 \mu \mathrm{m}$ PTFE membrane. The residual solid was dried and subjected to ICP analyses (SPS 4000, SII Nanotechnology, Chiba, Japan). All measurements were performed in duplicate.

\section{Photothermal properties of the SWNT- containing medium (in vitro)}

Cell culture medium (MEM-alpha, Invitrogen, Tokyo, Japan, containing $0.01,0.1,0.25$, and $0.5 \mathrm{mg} / \mathrm{mL}$ of the acid-treated SWNT and DNA-SWNT) was added to each well of a 48-well multiplate and then irradiated with NIR (4.0 W/cm², LA-100 IR, Hayashi, Tokyo, Japan). The light tip of the NIR apparatus was located at a distance of $2 \mathrm{~cm}$ from the surface of the medium solution in each well. Each medium solution $(n=3)$ was exposed to NIR light for up to 5 minutes, and the temperature rise of each medium solution and the medium alone were continuously measured using a thermometer (DP-700, RKC, Tokyo, Japan) with a thermocoupled probe (JB-16, RKC, Tokyo, Japan) as described in the schematic diagram (Figure 1).

\section{Photothermal properties of the SWNT-containing gel (in vivo)}

Animal experiments were performed in accordance with the ethical guidelines for animal experiments of Fukuoka

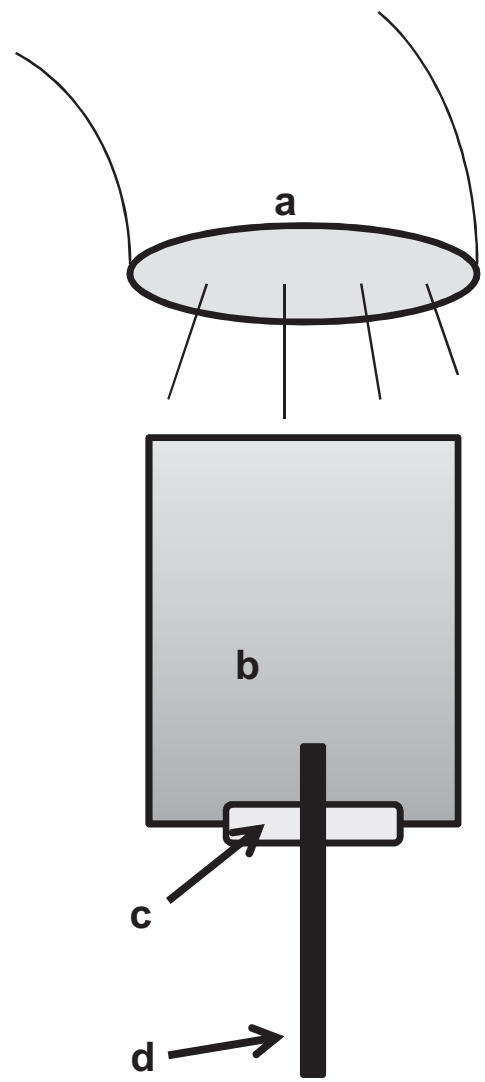

Figure I Schematic diagram of the heat measurement, showing the light tip of near-infrared light source (a), the culture medium in a well of multiplate (b), the silicon rubber packing (c), and the inserted probe of the thermometer (d).

Dental College. Heat generation in vivo was measured using 6-week-old C57BL/6 mice. Mixtures of the SWNTs (acid-treated and DNA-SWNTs) and basement membrane matrix (BD Matrigel, BD, USA) with the SWNT concentrations of $0.01,0.1,0.25$, and $0.5 \mathrm{mg} / \mathrm{mL}$ were prepared, and then packed in a pre-cooled syringe before use. This mixture $(500 \mu \mathrm{L})$ was injected in the back of mice $(n=3)$ under general anesthesia induced by $2 \%$ isoflurane (Abbott Laboratories, Abotto Park, IL, USA) in an air mixture gas flow of $1.0 \mathrm{~L} / \mathrm{min}$ using an anesthesia gas machine (Anesthesia machine SF-B01, MR Technology, Tsukuba, Japan). After the temperature of the injected SWNT-containing gel equilibrated to the body temperature of the mouse (approximately 30 minutes after the injection), the probe of the thermometer was inserted into the injected gel. The light tip of the NIR apparatus was positioned at a distance of $2 \mathrm{~cm}$ from the body surface on the back of the mouse, and then the temperature rise by NIR irradiation was monitored for up to 5 minutes. The measurement was repeated three times for each condition.

Thermal images of the mouse when irradiated by the NIR light were captured by thermography (Thermoshot F30, NEC/ Avio, Tokyo, Japan), and the thermal distribution analyzed 
by analysis software (InfRec Analyzer NS9500, NEC/Avio, Tokyo, Japan).

\section{Statistical analysis}

A statistical analysis was performed using one-way ANOVA for the in vitro and in vivo heat generations at 5 minutes by the NIR irradiation, followed by Scheffe's multiple comparison test at the $5 \%$ level of significance.

\section{Results}

\section{Morphology and structural observation of SWNT}

A typical TEM image of the untreated SWNT is shown in Figure 2A, in which a highly bundled SWNT structure is observed. The length of each SWNT could not be identified because the SWNT formed aggregated bundles. Figure 2B shows a TEM image of the acid-treated SWNTs. The acidtreated SWNTs had a well-dispersed nature with shorter lengths (average value was $330 \pm 68 \mathrm{~nm}$, randomly calculated from 30 measurements of each SWNT). Figure 2C shows a TEM image of the DNA-SWNTs. There was no obvious morphological difference between the acid-treated SWNT and the DNA-SWNT.

Kuwahara et $\mathrm{al}^{21}$ assumed that the SWNTs are constructed from 74,000 carbon atoms $(1.0 \mathrm{~nm}$ diameter and $660 \mathrm{~nm}$ length). Based on the results, we estimated that the acidtreated SWNTs with a length of $330 \mathrm{~nm}$ has 37,000 carbon atoms (molecular weight of approximately 444,000).

\section{Dispersion stability of SWNT in culture medium}

The change in transmittance of the culture medium containing the SWNTs is shown in Figure 3. Although the acid-treated SWNT-containing medium rapidly increased the transmittance within 1 hour, suggesting aggregation of the SWNTs, the transmittance of the DNA-SWNT-containing medium did not change even after 48 hours. A microphotograph of the acid-treated SWNT-containing culture medium after 1 hour showed the highly aggregated nature of the SWNT. In contrast, for the medium containing the DNASWNT, no aggregated particles were visible (Figure 4).

\section{Binding ratio of SWNT and DNA}

From a quantitative analysis of the phosphorous, the DNASWNT contained 5.41\% phosphorous. The SWNT/DNA binding ratio was calculated based on the following formula ${ }^{22}$ for the percentage phosphorous:

$$
\mathrm{P}(\%)=\mathrm{pN} /(\mathrm{DN}+\mathrm{C}) \times 100,
$$

where $\mathrm{P}(\%)$ is the percent measured phosphorous $(5.41 \%)$, $\mathrm{p}$ is the weight of the phosphorous $(18,600)$ in one mole of DNA, D is the molecular weight of the DNA $(198,000), C$ is the molecular weight of the acid-treated SWNTs $(444,000)$, and $\mathrm{N}$ is the number of DNA molecules bound to each acidtreated SWNT molecule. When solved for N, the number of DNA molecules bound to the acid-treated SWNTs was calculated to be 3.1 . We estimated that approximately three molecules of DNA (300 bp) were bound to one acid-treated SWNTs, and the interaction between the DNA and the acidtreated SWNT would improve the dispersion stability.

\section{In vitro exothermic properties}

Thermal generation was observed during the NIR irradiation. The temperature of culture medium containing the acid-treated SWNTs was increased by prolonging the irradiation time (Figure 5A). With 5 minutes irradiation, the temperature of the
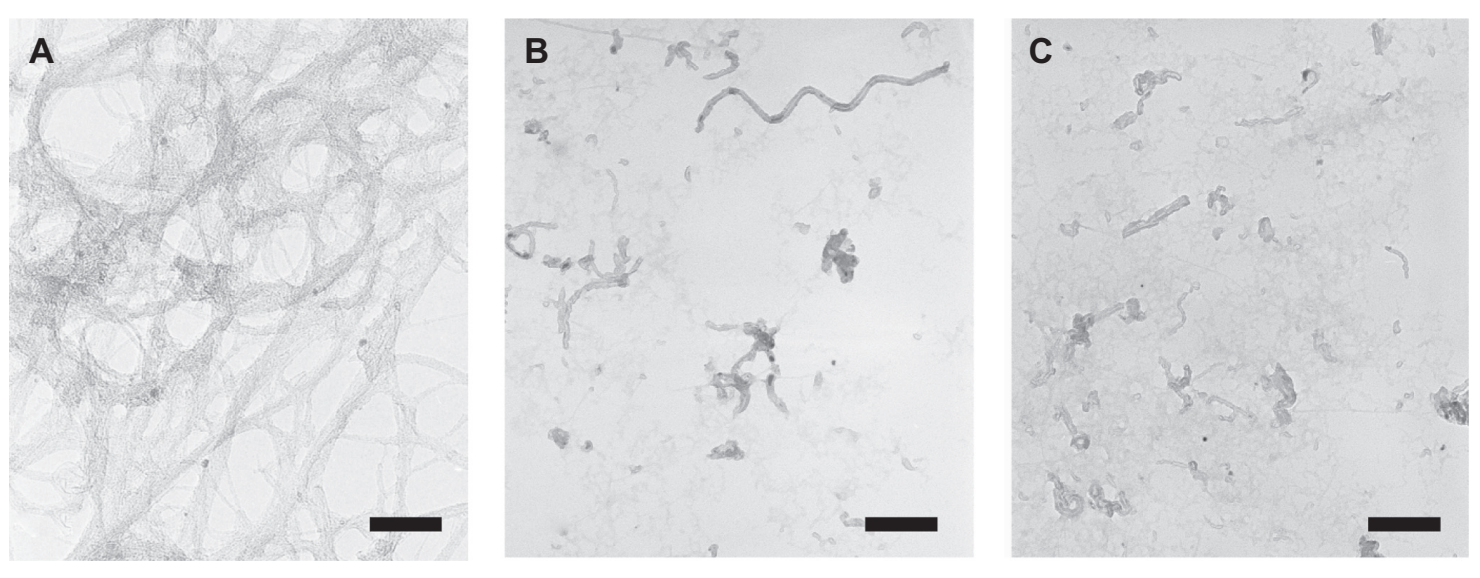

Figure 2 Typical transmission electron microscopy images of untreated single-walled carbon nanotubes (SWNTs) (A), the acid-treated SWNTs (B), and DNA-SWNTs (C). Scale bars $=50 \mathrm{~nm}$. 

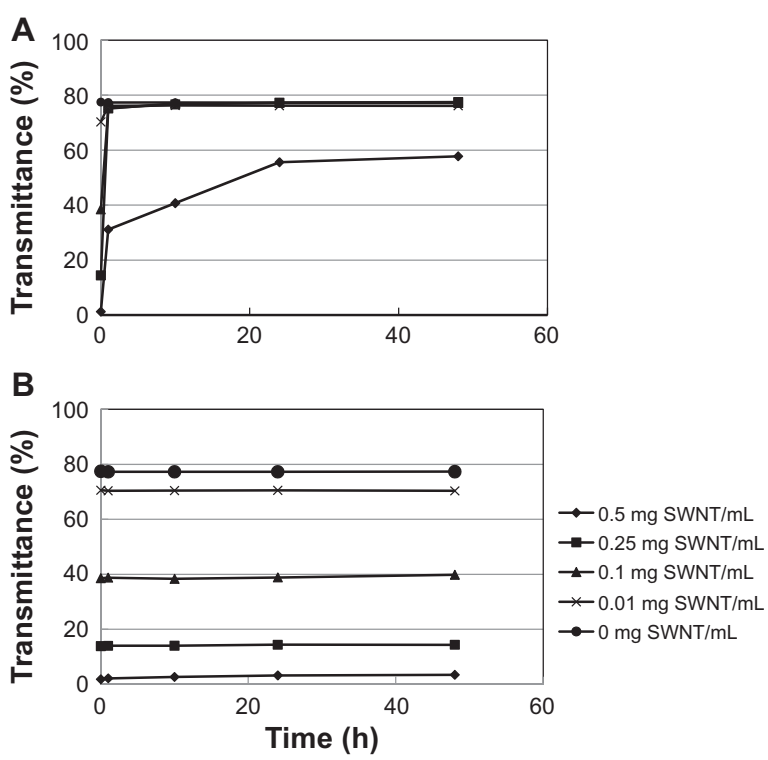

Figure 3 Change in transmittance (\%) of the culture medium containing the acid-treated SWNTs $(\mathbf{A})$ and the DNA-SWNTs (B).

Abbreviation: SWNT, single-walled carbon nanotube.

culture medium containing the acid-treated SWNT $(0.5 \mathrm{mg}$ $\mathrm{SWNT} / \mathrm{mL}$ ) reached $63^{\circ} \mathrm{C}$ from $28^{\circ} \mathrm{C}$ (temperature before irradiation), a $35^{\circ} \mathrm{C}$ temperature change, while the culture medium alone showed only a $14^{\circ} \mathrm{C}$ temperature rise. There were significant differences among the mediums containing the SWNTs $(0.01,0.1,0.25$, and $0.5 \mathrm{mg} \mathrm{SWNT} / \mathrm{mL})$ and control $(P<0.05)$. However, the acid-treated SWNTcontaining medium $(0.1,0.25$, and $0.5 \mathrm{mg} / \mathrm{mL}$ of SWNTs) showed indistinguishable temperature-irradiation time curves except for the lower $(0.01 \mathrm{mg} / \mathrm{mL}) \mathrm{SWNT}$ one.

The DNA-SWNT-containing medium showed a maximum temperature rise of $38^{\circ} \mathrm{C}$ after 5 minutes of irradiation (Figure 5B). There were significant differences between the temperature of medium containing DNA-SWNT and that without the SWNT after 5 minutes, except for the samples with a $0.01 \mathrm{mg} / \mathrm{mL}$ SWNT concentration and medium only $(P<0.05)$. The temperature rise of the medium
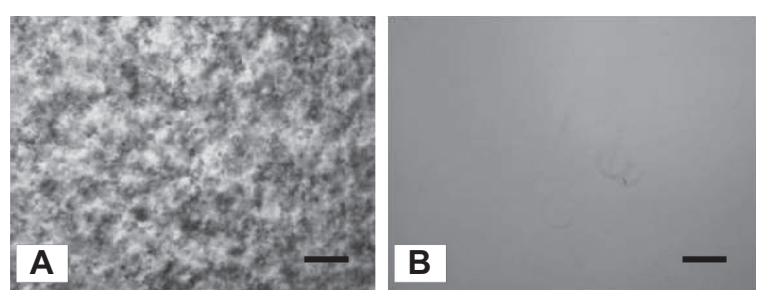

Figure 4 Typical microscopic images of culture medium containing the acid-treated SWNT (A) and the DNA-SWNTs (B).

Notes: Scale bars $=100 \mathrm{~mm}$. These images were observed at 5 minutes after the mixture of the acid-treated SWNT (or DNA-SWNT), and medium was prepared using a microscope (TS-100, Nikon, Tokyo Japan).

Abbreviation: SWNT, single-walled carbon nanotube.
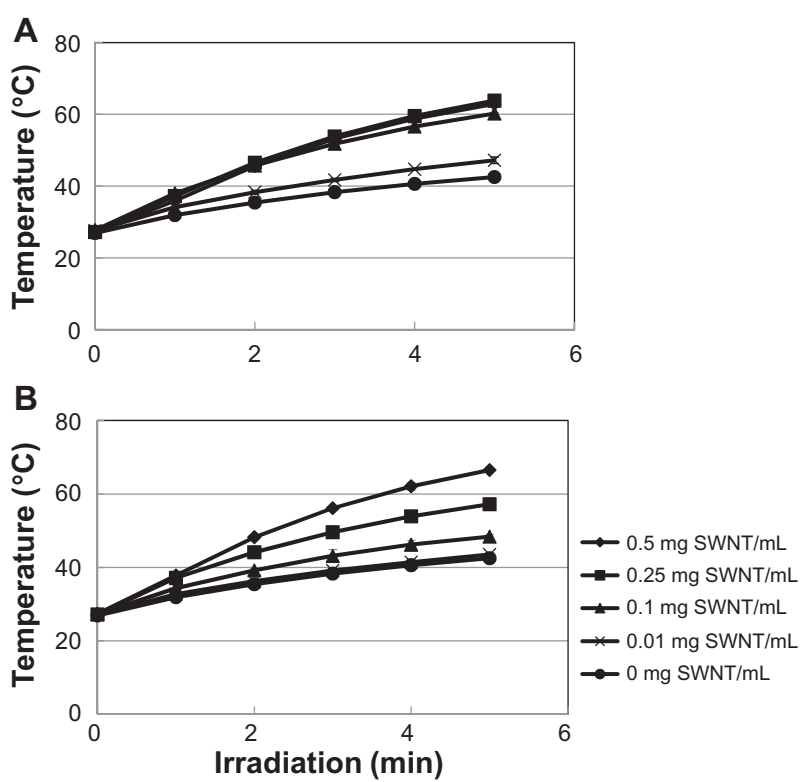

Figure 5 In vitro exothermic heat generation of the acid-treated SWNTs (A) and the DNA-SWNTs (B). The heat evolution was dependent on the exposure time of the near-infrared light.

Abbreviation: SWNT, single-walled carbon nanotube.

containing the DNA-SWNTs was clearly dependent upon the SWNT concentration.

\section{In vivo exothermic properties}

The heat generation of the SWNT (acid-treated SWNT and DNA-SWNT)-containing gel in the back of the mouse is shown in Figure 6. For the acid-treated SWNT sample with a 5-minute irradiation period, there was no significant
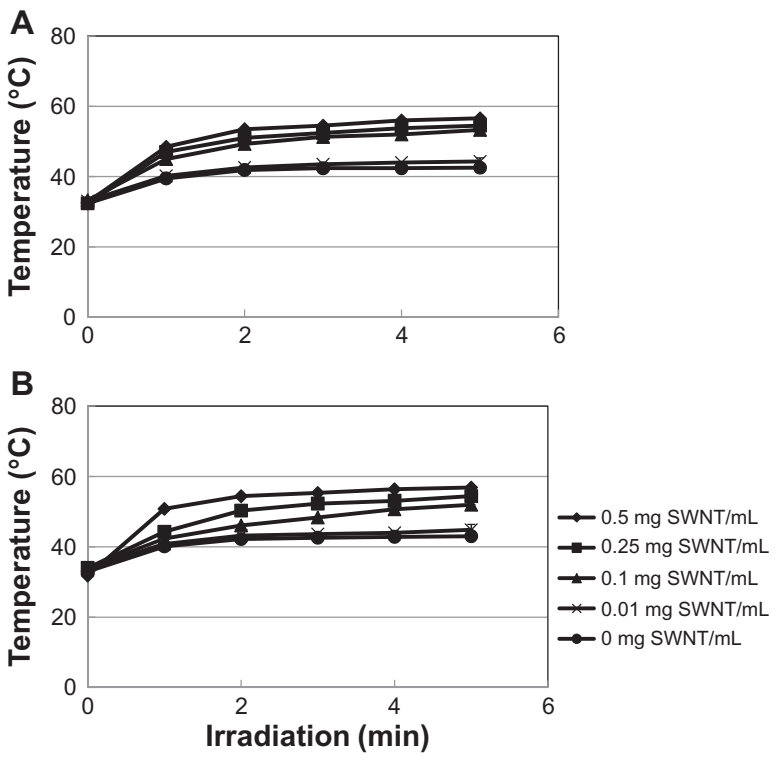

Figure $\mathbf{6}$ In vivo exothermic heat generation of the acid-treated SWNT (A) and the DNA-SWNT (B)

Abbreviation: SWNT, single-walled carbon nanotube. 
difference $(P>0.05)$ between the $0.01 \mathrm{mg} / \mathrm{mL}$ sample and control (without SWNT). However, there were significant differences between the SWNT samples $(0.1,0.25$, and $0.5 \mathrm{mg} / \mathrm{mL}$ ) and control.

The DNA-SWNT-containing gel with a 5-minute irradiation, except for the $0.01 \mathrm{mg} / \mathrm{mL}$ sample and the control (not significant, $P>0.05$ ), showed a significant concentrationdependent temperature rise among the control, $0.1,0.25$, and $0.5 \mathrm{mg} / \mathrm{mL}$ DNA-SWNT groups $(P<0.05)$, while the gel containing the acid-treated SWNTs did not show such an obvious profile. Although the peak temperature was obtained after the 5-minute irradiation at the concentration of $0.5 \mathrm{mg} / \mathrm{mL}$ for both the acid-treated and the DNASWNT, there was no difference between these SWNT types $(P>0.05)$. The results of multiple comparison test at the $5 \%$ level of significance of the peak temperature of each sample with a 5-minute irradiation was summarized in Table 1.

Thermal images of the mouse injected with the gel when NIR irradiated for 3 minutes are shown in Figure 7. For the injected gel alone (Figure 7A), the thermal image revealed a thermal distribution of approximately $39^{\circ} \mathrm{C}$ in the irradiated area. In contrast, the thermal image of mouse injected with the gel containing the acid-treated SWNT (Figure 7B) and the DNA-SWNT (Figure $7 \mathrm{C})(0.5 \mathrm{mg} / \mathrm{mL})$ showed a higher thermal distribution (above $50^{\circ} \mathrm{C}$ ).

\section{Discussion}

Our strategy is that the SWNT could be used as an exothermic molecular device for hyperthermia cancer therapy. For attaining a good performance by the SWNT-based heating device, two main approaches should be discussed: 1) to improve the solubility for the stable and good dispersibility of the SWNT in body fluids, and 2) to obtain a selective targeted cell attaching ability of the SWNTs by surface functionalization. Based on these requirements, as a first step, we investigated the exothermic heat generation of the acid-treated and the DNA-SWNT using NIR irradiation.
As can be seen in Figure 2A, the native SWNT has a strong tendency to bind together and aggregate due to their van der Waals attractive forces, and this aggregate structure makes the SWNT insoluble in aqueous solution. ${ }^{23}$ It has been shown that the acid treatment of CNTs with sulfuric acid and nitric acid opens up the aggregate structure, reduces the CNT length, and facilitates dispersion. ${ }^{16}$ The TEM image in Figure 2B revealed that the acid-treated SWNT formed a well-dispersion in aqueous solution with a shorter length.

Several researchers have reported the potential use of SWNTs for cancer treatment by exothermal generation induced by NIR laser irradiation. ${ }^{3-5}$ Kam et $\mathrm{al}^{5}$ reported that continuous NIR irradiation can cause cell death due to excessive local heating of the SWNTs in vitro. They suggested that if the SWNTs can be selectively internalized into cancer cells with specific tumor markers, NIR irradiation of the SWNT can selectively trigger thermal cell death without harming normal cells. Zhou et $\mathrm{al}^{6}$ prepared the conjugate of the SWNTs and folate moiety, which selectively internalized the SWNT inside cells labeled with folate receptor tumor markers. The SWNT-folate conjugate enhanced the photothermal destruction of tumor cells (EMT6, mammary tumor cell) by a 980-nm NIR laser irradiation. In these studies, the NIR laser was used as the light source because the SWNT has a strong optical absorption in the visible and NIR ranges. We used a halogen lamp unit as the NIR light source with a wavelength range from 820 to $1100 \mathrm{~nm}$ (cutoff light below $800 \mathrm{~nm}$ wavelength using an optical filter). Because the SWNT has a strong optical absorbance in the NIR region, a light source with the wavelengths from 820 to $1100 \mathrm{~nm}$ would have the potential for heat generation. Our in vitro and in vivo data suggested that the halogen light source generates heat induced by the SWNTs. Biological tissues exhibited a deep penetrability with a very low absorption of NIR in the wavelength range of 700-1100 nm. ${ }^{24}$ For in vivo measurement, the gel containing SWNT was injected beneath the mouse epidermis. The thickness of the mouse epidermis was approximately $0.5 \mathrm{~mm}$. Irradiated NIR light

Table I Results of the statistical analysis for the exthothermic heat generation

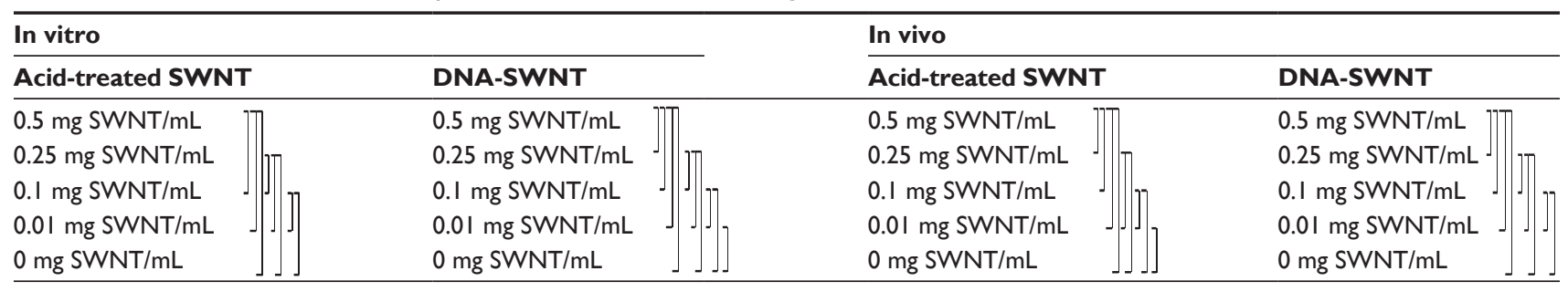

Notes: Each group represents the temperature after 5 minutes near-infrared irradiation of in vitro (Figure 5) and in vivo (Figure 6). Groups connected by bracket were significantly different $(P<0.05)$. 

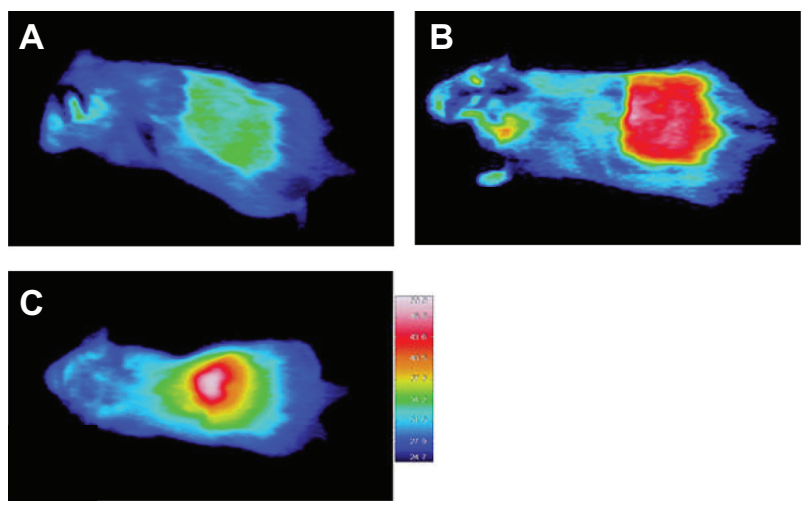

Figure 7 Thermal images of in vivo heat evolution in the subcutaneous tissues of a mouse. The acid-treated SWNT-containing gel (Matrige $\left.{ }^{\circledR}\right)(\mathbf{B})$ and the DNASWNT containing gel $(\mathbf{C})$ showed heat evolution over $50^{\circ} \mathrm{C}$ by the near-infrared irradiation. In contrast, no local heat evolution was found in gel (A) not containing the SWNTs.

Abbreviation: SWNT, single-walled carbon nanotube.

penetrated the epidermis of $0.5 \mathrm{~mm}$ thickness and generated exothermic heating of SWNTs. In our project, the SWNT hyperthermia therapy is targeted to tumors of intraoral tissue such as tongue, gingiva, and oral mucosa. Therefore, higher penetration ability of NIR light to tumors located in fairly deep portion beneath epidermis is not required. However, the effect of tissue thickness on thermal generation by using the halogen light source was not clear. Further investigations for this issue were needed. The heat generation in the nonSWNT area would have a noninvasive effect on the biological tissues during the halogen light NIR exposure. Based on the results of the current study, the halogen light unit would be an efficient light source for clinical use.

To use SWNTs for in vivo cancer treatment, a stable dispersion of the SWNTs in the body fluids is highly desirable. Aggregation of the SWNTs in the body fluid would hinder the smart delivery of the SWNTs to the tumors. In this study, we prepared the acid-treated SWNTs by treatment with sulfuric acid and nitric acid. However, as shown in Figure 4, when the acid-treated SWNTs were mixed with cell culture medium, the SWNT rapidly aggregated and black-colored precipitates were formed within 5 minutes. These precipitates suggested that the anionic carboxylic acid group formed on the SWNT surface reacted with some cationic species in the medium. As shown in Figure 5, the acid-treated SWNT-containing medium did not show clear concentration-dependent heat generation curves. In this case, the acid-treated SWNT formed aggregated particles, and accumulated in the bottom of the well. This precipitate formation caused nonuniform distribution of the SWNT in the medium, and could result in unclear concentration-dependent heat generation behavior of the acid-treated SWNT-containing medium.
On the other hand, stable dispersibility (uniform dispersion) of DNA-SWNT in the medium would contribute to the clear concentration-dependent heat generation behavior. The difference in the dispersion nature of the acid-treated SWNT and DNA/SWNT in cultural medium would reflect the heat generation behavior of the in vivo test shown in Figure 6 . The gel containing the acid-treated SWNT showed thermal generation behavior similar to the acid-treated SWNT-containing medium. This finding would be caused by the SWNT aggregation in the injected gel. These results suggested that the controlled thermal generation caused by SWNTs in the human body would require the stable dispersion of SWNTs in body fluid.

We applied the SWNT functionalization with doublestranded DNA (DNA-SWNT) to achieve a stable dispersion in the body fluids. No precipitate was formed using the mixture of the DNA-SWNT and the medium even after 5 days during storage at $37^{\circ} \mathrm{C}$ (Figure 3). DNA (double- and singlestranded) was used as an effective solubilization substance to modify the untreated SWNTs into water-soluble SWNTs. DNA would bind to the sidewall of the SWNTs through $\pi-\pi$ interactions. ${ }^{17,25}$ The DNA-SWNT prepared in this study showed an exothermic generation by NIR irradiation as did the acid-treated SWNTs. A concentration-dependent heat generation was clearly observed for the in vitro and in vivo measurements (Figures 5B and 6B). This result would be mainly due to the well dispersed nature of the DNA-SWNT in the culture medium and the injected gel.

Based on these results, the functionalization with DNA would be a useful approach to improve the low dispersibility of the acid-treated SWNTs in body fluids. Furthermore, the carboxylic acid groups formed on the surface of the solubilized SWNT may be used as conjugation sites to link other ligands to the SWNT surface using a carbodiimide reaction. ${ }^{26}$ The results of this study hinted that if the DNA/SWNT can be modified by the specific antibody of tumor cells, the DNA/ SWNT can selectively bind to the targeted cells and act as a heating device for hyperthermia therapy. The next stage of our study is to prepare the complex of the DNA/SWNT and the antibody, and to evaluate the selective binding ability, biodistribution, toxicity, and thermal generation of the complex in vitro and in vivo.

In summary, we have described the exothermic generation of acid-treated SWNTs by NIR irradiation. The results of this study suggested that the acid-treated SWNTs could be used as a hyperthermic molecular device for cancer treatment. Although, aggregated precipitations were formed in the culture medium for acid-treated SWNTs, this lower 
dispersibility was improved by functionalization with DNA (SNA-SWNT). The DNA-SWNT showed a controlled heat generation with the SWNT concentration, and would be an appropriate heating device by NIR irradiation in the body fluids.

\section{Disclosure}

The authors report no conflicts of interest in this work.

\section{References}

1. Dhar S, Liu Z, Thomale J, Dai H, Lippard SJ. Targeted single-wall carbon nanotube-mediated Pt (IV) prodrug delivery using folate as a horming device. J Am Chem Soc. 2008;130:11467-11476.

2. Liu Z, Che K, Davis C, et al. Drug delivery with carbon nanotubes for in vivo cancer treatment. Cancer Res. 2008;68:6652-6660.

3. Liu Z, Tabakman S, Welsher K, Dai H. Carbon nanotubes in biology and medicine: in vitro and in vivo detection, imaging and drug delivery. Nano Res. 2009;2:85-120.

4. O'Connell MJ, Bachilo SM, Huffman CB, et al. Band gap fluorescene from individual single-walled carbon nanotubes. Science. 2002;297: 593-596.

5. Kam NWS, O'Connell M, Wisdom JA, Dai H. Carbon nanotubes as multifunctional biological transporters and near-infrared agents for selective cancer cell destruction. Proc Natl Acad Sci U SA. 2005;102: 11600-11605.

6. Zhou F, Xing D, Ou Z, Wu B, Resasco D, Chen WR. Cancer photothermal therapy in the near-infrared region byb using single-walled carbon nanotubes. J Biomed Optics. 2009;14:021009.

7. Ji S, Liu C, Zhang B, et al. Carbon nanotubes in cancer diagnosis and therapy. Biochim Biophys Acta. 2010;1806:29-35.

8. Kam NWS, Jessop TC, Wender PA, Dai H. Nanotube molecular transporters: Internalization of carbon nanotube-protein conjugates into mammalian cells. J Am Chem Soc. 2004;126:6850-6851.

9. Dumortier H, Lacotte S, Pastorin G, et al. Functionalized carbon nanotubes are non-cytotoxic and preserve the functionality of primary immune cells. Nano Lett. 2006;6:1522-1528.

10. Kawaguchi M, Fukushima T, Hayakawa T, et al. Preparation of carbon nanotube-alginate nanocomposite gel for tissue engineering. Dent Mater J. 2006;25:719-725.
11. Sayes CM, Liang F, Hudson JL, et al. Functionalization density dependence of single-walled carbon nanotubes cytotoxicity in vitro. Toxicol Lett. 2006;161:135-142.

12. Wu P, Chen X, Hu N, et al. Biocompatible carbon nanotubes generated by functionalization with glycodendrimers. Angew Chem Int Ed. 2008; 47:5022-5025.

13. Schipper ML, Nakayama-Ratchford N, Davis CR, et al. A pilot toxicology study of single-walled carbon nanotubes in a small sample of mice. Nat Nanotech. 2008;3:216-221.

14. An KH, Jeon KK, Moon J-M, et al. Transformation of singlewalled carbon nanotubes to multiwalled carbon nanotubes and onion-like structures by nitric acid treatment. Synthetic Met. 2004;140:1-8.

15. Kordas K, Mustonen T, Toth G, et al. Inkjet printing of electrically conductive patterns of carbon nanotubes. Small. 2006;2:1021-1025.

16. Daniel S, Rao TP, Rao KS, et al. A review of DNA functionalized/ grafted carbon nanotubes and their characterization. Sens Actuators $B$. 2007;122:672-682.

17. Nakashima N, Okuzono S, Murakami H, Nakai T, Yoshizawa K. DNA dissolves single-walled carbon nanotubes in water. Chem Lett. 2003;32: 456-457.

18. Zheng M, Jagota A, Semke ED, et al. DNA-assisted dispersion and separation of carbon nanotubes. Nat Mater. 2003;2:338-342.

19. Noguchi Y, Fujigaya T, Niidome Y, Nakashima N. Single-walled carbon nanotubes/DNA hybrids in water are highly stable. Chem Phys Lett. 2008;455:249-251.

20. Tu X, Zheng MA. DNA-based approach to the carbon nanotube sorting problem. Nano Res. 2008;1:185-194.

21. Kuwahara S, Sugai T, Shinohara H. Determining exact molar absorbance coefficients of single-wall carbon nanotubes. Phys Chem Chem Phys. 2009;11:1091-1097.

22. Fukushima T, Hayakawa T, Okamura K, et al. Buffer solution can control the porosity of DNA-chitosan complexes. J Biomed Mater Res B Appl Biomater. 2006;76B:121-139.

23. Dyke CA, Tour JM. Covalent functionalization of single-walled carbon nanotubes for materials applications. $J$ Phys Chem. 2004;108: 11151-11159.

24. König K. Multiphoton microscopy in life sciences. J Microsc. 2000;200: 83-104.

25. Fujigaya T, Nakashima N. Methodology for homogeneous dispersion of single-walled carbon nanotubes by physical modification. Polymer $J$. 2008;40:577-589.

26. Hermanson GT. Bioconjugate techniques. 2nd ed. Amsterdam: Elsevier; 2008:638-648.
International Journal of Nanomedicine

\section{Publish your work in this journal}

The International Journal of Nanomedicine is an international, peerreviewed journal focusing on the application of nanotechnology in diagnostics, therapeutics, and drug delivery systems throughout the biomedical field. This journal is indexed on PubMed Central, MedLine, CAS, SciSearch ${ }^{\circledR}$, Current Contents ${ }^{\circledR} /$ Clinical Medicine,

\section{Dovepress}

Journal Citation Reports/Science Edition, EMBase, Scopus and the Elsevier Bibliographic databases. The manuscript management system is completely online and includes a very quick and fair peer-review system, which is all easy to use. Visit http://www.dovepress.com/ testimonials.php to read real quotes from published authors. 